\title{
Operative Therapy of Achilles Tendon Rupture - A Critical Questioning of the Actual Literature
}

\author{
Simone Frunz ${ }^{1}$, Markus Knupp ${ }^{2,3}$, Beat Göpfert and Lukas D Iselin ${ }^{1,2^{*}}$ \\ ${ }^{1}$ Department of Orthopedics and Traumatology, Lucerne Cantonal Hospital, Switzerland \\ ${ }^{2}$ Mein Fusszentrum AG, Eichenstrasse 31, 4054 Basel, Switzerland \\ ${ }^{3}$ Department of Human Medicine, University of Basel, Switzerland \\ ${ }^{4}$ Department of Biomedicine, University of Basel, Switzerland
}

\begin{abstract}
Background: The current literature shows that operative treatment has advantages in comparison to conservative treatment for acute Achilles tendon ruptures and there is a large amount of biomechanical cadaver studies which examined the strength of several suture techniques to determine the best suture technique for operative treatment of Achilles tendon rupture. The goal of our study was to compare two different suture materials regarding their strength properties.

Methods: Ten pairs of fresh frozen Achilles tendons were obtained from human donors (41-85 years). The tendons were fixed on a testing machine and loaded until failure. The goal of this setup was to obtain a natural rupture pattern. The ruptured tendons were sutured either with BB MonoMax or PDS and again loaded until failure.

Results: The ruptures occurred on different locations. The failure mode in all sutured tendons was a pullout of the suture material through the tendon fibers.

Discussion: Due to the failure mode it was not possible to compare the two different suture materials regarding their strength properties. Regarding this result it might be that the in vivo pullout strength of the common Achilles tendon suture techniques is not as high as it is detected in most biomechanical cadaver studies.
\end{abstract}

\section{Keywords}

Achilles Tendon rupture, Suture technique, Suture material

\section{Background}

The rupture of the Achilles tendon is one of the most common tendon ruptures [1].

The injury occurs most frequently in middle-aged man (30-45 years) [2].

In the current development with increased life expectancy in combination with an increased athletic demand upon the aging body, the incidence of Achilles tendon ruptures is also expected to increase $[3,4]$.

There is no consensus on the treatment of acute Achilles tendon ruptures. While some surgeons prefer conservative treatment to avoid complications from surgery, most physicians consider operative treatment to be more reliable in young and mid-aged patients. The latter has been shown to reduce the risk of rerupture by the factor 3 . Moreover, surgical treatment may allow earlier return to work and shows a better range of motion in the ankle $[2,5,6]$.

Early functional postoperative treatment with mobilization and weight bearing also leads to better functional out- comes compared to immobilization and partial weight bearing after operation [2].

Early mobilization after surgery relies on a strong repair of the achilles tendon. The rate of failure is influenced by the surgical technique and the suture material [7]. Whereas several studies have assessed different suture techniques only limited data is published on different suture material.

Therefore we wanted to compare two different suture

*Corresponding author: Dr. Lukas D Iselin, Department of Orthopedics and Traumatology, Lucerne Cantonal Hospital, Spitalstrasse 16, 6000 Lucerne, Switzerland; Department of Biomedicine, University Hospital Basel, University of Basel, Hebelstrasse 20, 4031 Basel, Switzerland, Tel: +41412054873

Accepted: September 15, 2020

Published online: September 17, 2020

Citation: Frunz S, Knupp M, Göpfert B, et al. (2020) Operative Therapy of Achilles Tendon Rupture - A Critical Questioning of the Actual Literature. Adv Tech Musculoskelet Surg 4(1):36-40 


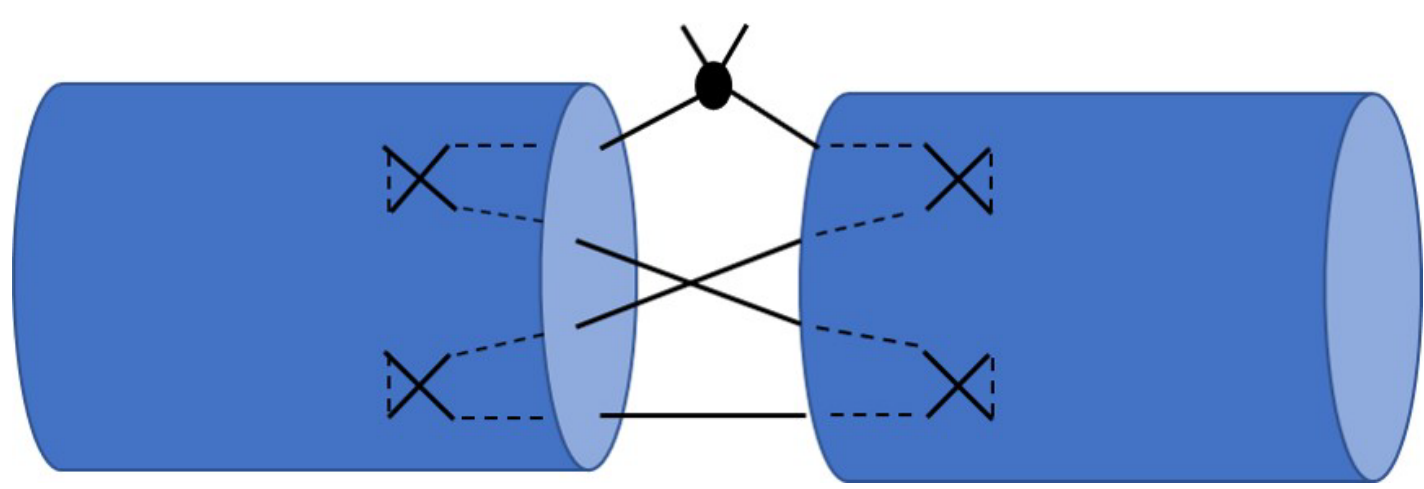

Figure 1: Adelaide suture technique.

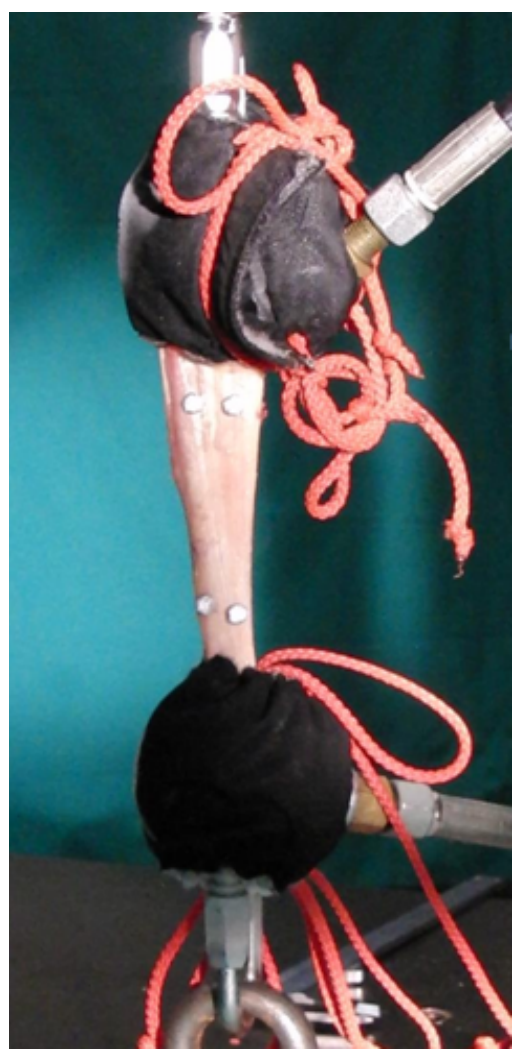

Figure 2: Mounted nativ Achilles tendon during cooling process with liquid $\mathrm{CO}_{2}$.

materials regarding their strength properties. We used the four-strand Adelaide suture (Figure 1 ) to readapt the end of the torn tendons $[8,9]$.

\section{Methods}

The tests were performed at the Center of Biomechanics at the University of Basel according to the rules of the permission of the local ethical commission (EK 341/13). Ten pairs of fresh frozen Achilles tendons were obtained from human donors aged 41-85 within 12 hours after death. Inclusion and exclusion criteria are listed in Table 1.

The specimens contained part of the posterior half of the calcaneus and extended proximally to the musculo-tendinous transition point.
The tendons were fixated to the clamps of the testing machine. As a final step we used liquid $\mathrm{CO}_{2}$ to achieve a strong fixation (Figure 2).

Before testing, two reflecting markers (d: $6.5 \mathrm{~mm}$, Prophysics $A G$, Kloten $\mathrm{CH}$ ) were fixed to the tendon about $2 \mathrm{~cm}$ below resp. above the clamps, using cyanoacrylate glue (LOCTITE 401, Henkel \& Cie. AG, Pratteln CH). These four markers were tracked during different loading conditions with six high-speed digital cameras (MX-13 + Sampling rate $30 \mathrm{~Hz}$, Vicon Motion Systems Ltd., Oxford, UK). The placement of the markers and the force measured by the load cell were recorded synchronously with the motion analysis system (Nexus, Vicon Motion Systems Ltd., Oxford, UK).

The following steps were performed:

1. Preloading the native tendon with $1 \mathrm{~Hz}$ between 100 and $800 \mathrm{~N}$ over 20 cycles.

2. Loading until failure with $10 \mathrm{kN} / \mathrm{sec}$.

Due to the variance of the location where the ruptures occurred we decided to weaken the last four specimens at the favored point in the mid tendon part (Table 2).

Therefore we performed an artificial incision with a scalpel $(5 \mathrm{~mm})$ in the mid tendon part.

3. Suturing of the ruptured tendon with the Adelaide suture (four-strand cross-locked suture technique). From every human donor, we sutured one tendon with B Braun; MonoMax HRT 40s; Size: 1 (BB) and one tendon with Ethicon; PDS CTX; Size: 1 (PDS)

4. Preloading the sutured tendon with $1 \mathrm{~Hz}$ between 50 and $100 \mathrm{~N}$ over 20 Cycles

5. Loading until failure with $10 \mathrm{kN} / \mathrm{sec}$.

The maximal force until failure of the native tendon was recorded and for the sutured tendon the force-displacement diagram of the loading cycles until failure was analyzed.

\section{Results}

\section{Creation of the rupture}

The measured force at the time of rupture ranges between $2408 \mathrm{~N}$ and $5972 \mathrm{~N}$. The area of failure varies within the 
Table 1: Inclusion and Exclusion criteria.

\begin{tabular}{|c|c|}
\hline Inclusion & Exclusion \\
\hline Consent to the autopsy by a legal proxy & $\begin{array}{l}\text { - Known Achilles tendon rupture } \\
\text { - Tumour affecting the Achilles Tendon } \\
\text { - Rheumatoid/vasculitic disorder spectrum (Rheumatoid Arthritis, Lupus, Psoriasis), } \\
\text { - } \quad \text { Othdocrine Diseases (e.g. gout) } \\
\text { local infection or inflammation, skin lesion) } \\
\text { - Acute joint infection or previous joint infection of the upper ankle joint. }\end{array}$ \\
\hline
\end{tabular}

Table 2: failure load of native Achilles tendon.

\begin{tabular}{|l|l|l|l|l|}
\hline Specimen No. & $\begin{array}{l}\text { Sample Side } \\
\mathbf{1}[\mathbf{N}]\end{array}$ & Failure location & Sample Side $\mathbf{2}$ [N] & Failure location \\
\hline $\mathbf{1}$ & 3263 & At an artificial made incision mid tendon & 2614 & At an artificial made incision mid tendon \\
\hline 2 & 2463 & At an artificial made incision mid tendon & 2785 & At an artificial made incision mid tendon \\
\hline 3 & 5972 & proximal part & 5500 & proximal part \\
\hline 4 & 4743 & proximal part & 4299 & proximal part \\
\hline 5 & 3884 & Tendon-muscle interface & 5287 & Tendon-muscle interface \\
\hline 6 & 4066 & Pull-Out-Rupture at the proximal clamp & 5103 & Pull-Out-Rupture at the proximal clamp \\
\hline $\mathbf{7}$ & 3786 & Close to frozen area & 4543 & Close to frozen area \\
\hline 8 & 2408 & Close to frozen area & 5821 & mid tendon \\
\hline 9 & 3710 & Distal part tendon -bone interface & 4997 & mid tendon \\
\hline 10 & 3079 & Distal part tendon -bone interface & 3942 & Close to frozen area \\
\hline $\begin{array}{l}\text { Average force } \\
\text { until failure }\end{array}$ & & $\mathbf{4 1 1 3}$ [N] SD: $\mathbf{1 0 9 1}$ [N] & & \\
\hline
\end{tabular}

different tendons. Two tendons ruptured at the distal part of the tendon-bone interface $(3786 \mathrm{~N}, 2408 \mathrm{~N})$. Two tendons ruptured in the mid tendon part $(5821 \mathrm{~N}, 4997 \mathrm{~N})$. Four tendons ruptured in the proximal part (5972N, 5500N, 4299N, 4743N). Two tendons ruptured at the tendon muscle interface $(3884 \mathrm{~N}$, $5287 \mathrm{~N})$. Four tendons ruptured close to a frozen area (3786N, $2408 \mathrm{~N}, 4543 \mathrm{~N}, 3942 \mathrm{~N})$. Two ruptures occurred as pull out ruptures at the proximal clamp (4066N, 5103N). Due to the variance of the location where the ruptures occurred we decided to weaken the last four specimens at the favored point in the mid tendon part. Therefore we performed an artificial incision with a scalpel $(5 \mathrm{~mm})$ in the mid tendon part. These four tendons ruptured at the side of the artificial incision in the mid tendon (3263N, 2463N, 2614N, 2785N) (Table 2).

\section{Testing of the reconstruction}

The maximal forces in the sutured tendons occurring at the rupture were for the BB-suture between $144 \mathrm{~N}$ and 232 $\mathrm{N}$ (Mean 197 (SD 67) N) and for the PDS-suture between 158 $\mathrm{N}$ and $226 \mathrm{~N}$ (Mean 194 (SD 70) N). The failure mode showed no suture breakage. The main failure mode of the sutured tendons showed a tightening of the suture stitches and knots with a cutting into the tissue of the tendon along the tendons fibers and resulted in a suture pullout.

\section{Discussion}

The main difference between our setup and other studies is the preparation of the tendon rupture. The large amount of the existing literature simulated the Achilles tendon rupture by a sharp dissection 4-6 cm proximal to the calcaneal insertion [10-17]. Cretnik, et al. published a biomechanical study in 2000 where they were comparing the strength between the percutaneous Ma Griffith and a modified percutaneous Ma Griffith technique. They first performed the surgical procedure on the intact tendon and then made a sharp dissection $4.5 \mathrm{~cm}$ proximal to the calcaneal insertion, taking care not to injure the already applied suture [10]. Most authors described in their discussions the sharp preparation as a possible limitation or weakness of their study. For scientific reasons it makes sense to prepare the tendons always in the same way, so there are standardized conditions for a very specific question like the in vitro tensile strength of a particular technique. But this in vitro produced sharp dissection of the Achilles tendon has probably not much in common with a real traumatic Achilles tendon rupture with its "mop ends" appearance. In our setup, we wanted to create a natural rupture pattern. Therefore we put the tendon under maximal load until the rupture occurred. Although the setup was strictly standardized and the loading conditions were all the same, the ruptures appeared on different parts of the tendons. Due to the difficulty we experienced during the preparation of the ruptures we decided to weaken the last four specimens at the mid tendon portion with an artificial incision, to create a predetermined breaking point.

Due to the failure mode we were not able to compare the two different suture materials regarding their strength 
properties. We suspected a rupture of the suture material or a breakdown at the knot. But all sutures showed a pullout through the tendon as failure mode. With this result it is actually not possible to make a statement about the tensile strength of a suture material, because it seems that the mechanism of failure occurs in the combination of the ruptured tendon with the suture technique.

We assume that the Adelaide suture (four-strand cross-locking sutures) is an appropriate suture technique for Achilles tendon rupture. Therefore it might be that the strength of the common four-strand cross-locking sutures is in reality not as high as we expected it to be based on the results of most biomechanical cadaver studies.

\section{Limitations}

Our study has three major limitations. One is the utilization of the Adelaide suture. The most comparative biomechanical cadaver studies examined standard sutures like Krackow, Bunnell, Kessler and some percutaneous procedures.

Another limitation is the creation of the Achilles tendon rupture of the last four specimens, where we used a $5 \mathrm{~mm}$ long artificial incision to predetermine the location of the rupture. The third severe limitation is the small amount of specimen and the lack of statistical analysis due to this.

\section{Conclusion}

Despite the shortcomings of our study we want to share our considerations regarding the possible limitations of the existing literature. Most of the existing data regarding the strength properties of common Achilles tendon suture techniques were collected in standardized biomechanical cadaver studies. But their standard to simulate an Achilles tendon rupture with a sharp transection of the Achilles tendon has not much in common with an Achilles tendon rupture in a real patient with its "mop ends" appearance. Therefore we might consider that the strength of an Achilles tendon suture is not as high as we might suspect based on the data presented in research literature.

\section{Declarations}

\section{Ethics approval and consent to participate}

The tests were performed at the Center of Biomechanics at the University of Basel. Ethical committee approvement Nordwest- und Zentralschweiz - EKNZ (EK 341/13). According to the authorities no written consent for participating in the cadaver study was required additionally to the approval for the autopsy.

\section{Consent for publication}

Not applicable.

\section{Availability of data and materials}

The datasets used and/or analysed during the current study are available from the corresponding author on reasonable request.

\section{Competing interests}

The authors declare that they have no competing interests.

\section{Funding}

No funding.

\section{Authors contribution}

SF, LI have designed the study, SF, BG, MK and LI have conducted the analysis and measurements. SF, LI and MK have drafted the article.

\section{Acknowledgements}

Not applicable.

\section{References}

1. Kannus P, Józsa L (1991) Histopathological changes preceding spontaneous rupture of a tendon. A controlled study of $891 \mathrm{pa-}$ tients. J Bone Joint Surg Am 73: 1507-1525.

2. Braunstein M, Baumbach SF, Herterich V, et al. (2017) Die acute Achillessehnen ruptur. Wo stehen wir heute? Unfallchirurg 120: 1007-1014.

3. Huffard B, O' Loughlin P, Wright T, et al. (2008) Achilles tendon repair: Achillon system vs. Krackow suture: An anatomic in vitro biomechanic study. Clinical Biomechanics 23: 1158-1164.

4. Schepsis AA, Jnes H, Haas AL, et al. (2002) Achilles tendon disorders in athletes. Am J Sports Med 30: 287-305.

5. Erickson BJ, Mascarenahs R, Saltzman BM, et al. (2015) Is operative treatment of achilles tendon ruptures superior to nonoperative treatment?: A systematic review of overlapping meta-analyses. Orthop J Sports Med 3: 17.

6. Hess GW (2010) Achilles tendon rupture: A review of etiology, population, anatomy, risk factors, and injury prevention. Foot Ankle Spec 3: 29-32.

7. McCoy BW, Haddad SL (2010) The strength of achilles tendon repair: A comparison of three suture techniques in human cadaver tendons. Foot Ankle Int 31: 701-705.

8. Yildirim Y, Esemenli T (2002) Initial pull-out strenth of tendon sutures: An in vitro study in sheep Achilles tendon. Foot Ankle Int 23: 1126-1130.

9. Cretnik A, Zlajpah L, Smrkolj V, et al. (2000) The strength of percutaneous methods of repair of the Achilles tendon: A biomechanical study. Med Sci Sports Exerc 32: 16-20.

10. Demetracopoulos CA, Gilbert SL, Young E, et al. (2014) Limited-open achilles tendon repair using locking sutures versus nonlocking sutures: An In Vitro model. Foot Ankle Int 35: 612-618.

11. Heitman DE, Crivello KM, Gallina J, et al. (2011) Biomechanical comparison of the Achillon tendon repair system and the Krackow locking loop technique. Foot Ankle Int 32: 879-887.

12. Herbort M, Haber A, Zantop T, et al. (2008) Biomechanical comparison of the primary stability of suturing Achilles tendon rupture: $A$ cadaver study of Bunnell and Kessler techniques under cyclic loading conditions. Arch Orthop Trauma Surg 128: 1273-1277.

13. Labib SA, Rolf R, Dacus R, et al. (2009) The "Giftbox" repair of the Achilles tendon: A modification of the Krackow technique. Foot Ankle Int 30: 410-414.

14. Sadoghi P, Rosso C, Valderrabano V, et al. (2012) Initial Achilles tendon repair strenth--synhesized biomechanical data from 196 cadaver repairs. Int Orthop 36: 1947-1951.

15. Yammine K, Assi C (2017) Efficacy of repair techniques of the 
Citation: Frunz S, Knupp M, Göpfert B, et al. (2020) Operative Therapy of Achilles Tendon Rupture - A Critical Questioning of the Actual Literature. Adv Tech Musculoskelet Surg 4(1):36-40

Achilles tendon: A meta-analysis of human cadaveric biomechanical sutdies. Foot (Edinb) 30: 13-20.

16. Maquirriain J (2011) Achilles tendon rupture: Avoiding tendon lengthening during surgical repair and rehabilitation. Yale J Biol Med 84: 289-300.
17. Woo SL, Orlando CA, Camp JF, et al. (1986) Effects of postmortem storage by freezing on ligament tensile behavior. J Biomech 19: 399-404.

DOI: $10.36959 / 765 / 394$

Copyright: (c) 2020 Frunz S, et al. This is an open-access article distributed under the terms of the Creative Commons Attribution License, which permits unrestricted use, distribution, and reproduction in any medium, provided the original author and source are credited. 